\title{
Individual Differences in Children's and Parents' Generic Language
}

\author{
Susan A. Gelman \\ University of Michigan \\ Felicia Kleinberg \\ University of Michigan
}

\author{
Elizabeth A. Ware \\ Viterbo University \\ Erika M. Manczak \\ Northwestern University
}

\author{
Sarah M. Stilwell \\ University of Michigan
}

\begin{abstract}
Generics ("Dogs bark") convey important information about categories and facilitate children's learning. Two studies with parents and their 2- or 4-year-old children ( $N=104$ dyads) examined whether individual differences in generic language use are as follows: (a) stable over time, contexts, and domains, and (b) linked to conceptual factors. For both children and parents, individual differences in rate of generic production were stable across time, contexts, and domains, and parents' generic usage significantly correlated with that of their own children. Furthermore, parents' essentialist beliefs correlated with their own and their children's rates of generic frequency. These results indicate that generic language use exhibits substantial stability and may reflect individual differences in speakers' conceptual attitudes toward categories.
\end{abstract}

Language is a key mechanism for transmitting culturally important knowledge across generations (Gelman, 2009). For decades, scholars have noted that speakers' linguistic choices have consequences for everyday thought. For example, expressing a category with a noun versus an adjective or verbal phrase emphasizes the coherence and stability of the category (Cimpian, Arce, Markman, \& Dweck, 2007; Gelman \& Heyman, 1999; Walton \& Banaji, 2004; Waxman \& Leddon, 2011; Xu, 2007), expressing behaviors with more stable versus transient forms of the verb "to be" affects trait concepts (Heyman \& Diesendruck, 2002), and verb choice can influence causal attributions (Au, 1986; Brown \& Fish, 1983). Understanding when and how different aspects of language are used and how they relate to conceptual information can therefore

This research was supported by NICHD Grant R01 HD36043 to Gelman. We are grateful to all the parents and children who participated in the research. We thank Cara Brennan, Erin Boyle, Lindsay Hayes, Heather Hennrick, Melissa Herrett, Taylor Hicks, Courtney Hsing, Kara Kime, Christina Koch, and Amanda Markowitz for help with research assistance. Portions of these data were presented at the 2011 meeting of the Society for Research in Child Development.

Correspondence concerning this article should be addressed to Susan A. Gelman, Department of Psychology, University of Michigan, 350 Church St., Ann Arbor, MI 48109-1043. Electronic mail may be sent to gelman@umich.edu. provide great insight into how children acquire the knowledge systems of their culture.

One intriguing expression that has received recent interest from psychologists, linguists, and philosophers is that of generics (e.g., Dogs bark; $A$ dog is four legged; Carlson \& Pelletier, 1995; Cimpian \& Markman, 2008; Dahl, 1975; Gelman, 2003; Lawler, 1973; Leslie, 2007; Pelletier, 2010; Prasada, 2000). Generic statements refer to categories, and so may be instrumental in children's category learning. They are frequent even when speakers explicitly refrain from offering judgments about that category. For example, a parent who scrupulously avoids gender stereotyping nonetheless may use generic language about gender (e.g., "Can girls play football?"; Gelman, Taylor, \& Nguyen, 2004). These generic references imply that gender is an important category within which inferences can be made. It is unlikely that parents are aware of the implicit messages conveyed by their use of generics.

Generics are also interesting because they may reflect psychological essentialism. Essentialism is the implicit belief that certain categories (e.g., dog, woman, gold) are richly structured "natural kinds"

(C) 2013 The Authors

Child Development (c) 2013 Society for Research in Child Development, Inc. All rights reserved. 0009-3920/2014/8503-0008

DOI: $10.1111 /$ cdev.12187 
that are real, discovered in nature, and inferentially rich (Gelman, 2003; Medin, 1989). Furthermore, these natural kinds are thought to have an underlying causal "essence" that makes them the way they are. Some implications of essentialism are that category boundaries are rigid, that category members share deep similarities, and that surface appearances can be misleading regarding category membership. Although essentialism misrepresents reality in important respects (Leslie, 2007; Rhodes \& Gelman, 2009), it is nonetheless commonly evoked to understand both biological and social kinds (Gelman, 2003).

Generics are consistent with essentialism in two ways. First, they express inherent, nonaccidental properties. For example, the generic statement, "A dog has four legs," implies that four leggedness is a stable, core property of dogs (Cimpian \& Markman, 2009; Gelman \& Bloom, 2007; Graham, Nayer, \& Gelman, 2011; Hollander, Gelman, \& Raman, 2009). In contrast, the nongeneric statement, "A dog is missing," refers to a property that is only incidental to the category of dogs. Second, generics suggest minimal within-category variability and imply category-wide similarities that can override superficial variation. For example, the generic statement, "Dogs are fourlegged," implies an unvarying body type, despite the actual existence of three-legged dogs. Thus, generics express regularities despite the existence of exceptions, thereby focusing on within-category commonalities and glossing over differences.

Furthermore, generics imply even broader generalizability than they express (Cimpian, Brandone, \& Gelman, 2010). Although people produce generics to express a broad range of generalizations, including those based on regularities that occur relatively infrequently (e.g., "Sharks attack humans"), when people hear a novel generic, they tend to assume that it holds consistently for the vast majority of category members. In this way, generics imply a sameness among category members, consistent with the essentialist belief that a category has an underlying reality that transcends outward variation.

Because generics are consistent with essentialism, they may provide an important mechanism for transmitting essentialist ideas to children. When learning a new animal category, children who hear generics about that category (e.g., "Zarpies hate ice cream") treat the category as more richly structured than children who hear the same information in nongeneric form (e.g., "This zarpie hates ice cream"; Gelman, Ware, \& Kleinberg, 2010). Not only do children learn that the predicates apply broadly to the category (e.g., that even atypical zarpies hate ice cream) but also they infer that the category itself is more stable and inference promoting. The same effects are obtained when children are taught generics about novel social categories (e.g., people called zarpies; Rhodes, Leslie, \& Tworek, 2012). Moreover, when parents received an experimental manipulation that increased their essentialist beliefs about a novel social category, they produced more generics about that category when talking to their children (Rhodes et al., 2012). These results suggest a bidirectional causal link between generic language and essentialist beliefs, when examining language and beliefs about a particular novel category.

If generics are a mechanism for imparting essentialism, it is important to know whether individual parents differ in the generic input to their children; whether such differences are stable over time, contexts, and domains; and whether they correspond to children's own generic language. Evidence for the stability of individual differences in generic production would provide indirect evidence that generics are linked to underlying conceptual representations. Specifically, stable individual differences in generic usage would argue against the idea that generics simply reflect transient, superficial, contextual influences on speech, and may indicate that people's use of generics instead reflects a stable conceptual perspective, such as essentialism.

To date, little work has examined the frequency of generic production across speakers. Generics are universally expressed across the world's languages (Carlson \& Pelletier, 1995; Mannheim, Gelman, Escalante, Huayhua, \& Puma, 2011; Tardif, Gelman, $\mathrm{Fu}, \& \mathrm{Zhu}, 2012)$ and are relatively frequent, particularly within pedagogical contexts (Gelman, Ware, Manczak, \& Graham, 2013). For example, nearly all parents in a middle-class U.S. sample produced at least one generic within a brief (10-15 min) bookreading session (Gelman, Coley, Rosengren, Hartman, \& Pappas, 1998). However, prior research also found substantial variation across speakers. In one controlled, mother-child book-viewing study, the rate of generic production across individual mothers ranged from $0 \%$ to $41 \%$ of utterances (Pappas \& Gelman, 1998). Likewise, in a project examining parent-child conversations about gender in a naturalistic book-reading context, the rate of maternal generics across speakers ranged from $0 \%$ to $67 \%$ of all on-task utterances (Gelman et al., 2004). Even more remarkably, in the same study, the rate of child generics across speakers ranged from $0 \%$ to $92 \%$ of all on-task utterances. In a longitudinal examination of children's generics in a small sample 
of eight children ranging from 2 to 4 years of age, there were sizable individual differences in the rate of generic production as well: The rates at which children produced generics at age 2 ranged from under $0.2 \%$ of all utterances in one child to nearly $3 \%$ in another child; at age 3 , the rates varied from a low of $0.3 \%$ in one child to over $6 \%$ in another (Gelman, Goetz, Sarnecka, \& Flukes, 2008). Furthermore, the data suggested that these differences may be stable across time, as the rank ordering of the five children for whom data were available at all three ages (2, 3, and 4 years) was identical from year to year.

Although there may be stable individual differences in generic production, the evidence to date is limited to either a single point in time or a very small sample. Furthermore, individual differences may reflect uncontrolled situational factors. For example, a child may produce many generics because her conversational partner initiated a high rate of generic talk, or because she prefers topics that happen to support generics more easily (e.g., animals vs. artifacts; Brandone \& Gelman, 2009), or because she enjoys interactional contexts that are more pedagogical and thus evoke more generics (e.g., book reading vs. toy play; Gelman, Chesnick, \& Waxman, 2005; Gelman et al., 2013). It may also be that stability in the rates of generic production between the ages of 2-4 years discussed earlier (Gelman et al., 2008) reflects individual differences in early linguistic development, which will even out once children reach a certain level of fluency.

\section{The Present Studies}

The present studies were designed to examine whether individual differences in generic language production are stable across time, across domains, and across contexts, when controlling for potentially confounding factors, such as conversational partner or topic. We assessed stability over time (conversations held a few weeks apart) to assess test-retest reliability. If rate of generic language production is highly variable to momentary shifts in attention or experiences, then we would not expect stability over time. In contrast, if rate of generic language production is a stable individual difference, then we would expect significant correlations over time. We assessed stability over domains (e.g., animals vs. food) to determine whether rate of generics reflects domain-specific knowledge and interests versus a broader generic perspective. If generic rates reflect domain-specific factors, then a child who produces many generics about one domain (e.g., food) would not necessarily produce many generics about another domain (e.g., animals). In contrast, if generic rates reflect a broader conceptual perspective, then a child who produces many food-focused generics would be expected also to produce many animal-focused generics. Finally, we assessed stability over contexts (e.g., child talking with parent vs. researcher [Study 1]; parent-child dyad looking through pictures vs. playing with toys [Study 2]) to determine whether stability persists even in the face of different pragmatic demands, encouraging a speaker to be pedagogical versus playful versus analytic, and so forth. If pragmatic demands of the context primarily determine the rate of generics, then we would not expect consistency across contexts. However, if there are stable tendencies to be more or less generic, then we would expect consistency across contexts.

We also ask whether parents' generic usage correlates with their essentialism. We predicted that rates of generic production would correlate with beliefs that categories are stable, as generics express stability, from a semantic analysis. However, it was also of interest to test whether rates of generic production would correlate with a range of other essentialist beliefs, such as inheritance, inductive potential, and so forth. (see Gelman, 2003, for review).

We focused on preschool children and their parents. The parents provide evidence regarding not only the adult endpoint but also the language that children hear. The children provide evidence regarding individual differences early in development. Furthermore, by examining parents and their children, we are able to examine intergenerational relations in speech patterns. Study 1 examined 4-year-old children's and their parents' generics when in conversation with each other and a third, neutral party (a researcher), when engaged in a book-reading task at two distinct time points. We focused on 4-year-olds because they produce generics at roughly the same rate as adults (Gelman et al., 2008) and readily produce generics on an elicitation task (Brandone \& Gelman, 2009; Hollander, Gelman, \& Star, 2002), yet show tremendous individual variability in generic rates in natural language transcripts (Gelman et al., 2004). Study 2 examined 2- and 4-year-old children's and their parents' generics when engaged in conversation with each other when looking at pictures (pedagogical) and when playing with toys (nonpedagogical), to examine stability of individual differences across distinct contexts. We included 2-year-olds as well as 4-yearolds in Study 2 because the younger children are just beginning to produce generics and so 
provide important evidence regarding initial variation. The speech elicitation tasks varied two critical factors, conversational domain and context, that will be discussed at greater length in the Method sections.

\section{Study 1}

Method

\section{Participants}

Participants were 4-year-olds $(N=72 ; 36$ boys, 36 girls) and their parents $(N=72 ; 1$ father, 71 mothers). Children ranged in age from 4.0 to 5.0 at the first session (mean age $=4.6$ years at the first session; mean age $=4.7$ years at the second session). Children were primarily White (60 White, 2 African American, 1 Asian, 4 multiracial, 3 other, and 2 not reported). Parents ranged in age from 21 to 46 years (mean age $=36$ years) and were primarily White. An additional seven dyads were tested but not included because they could not be scheduled for their second visit within 4 weeks of their first visit.

\section{Materials}

Four different picture books were used, each with 15 pages. Each page depicted a full-color, realistic drawing of one item. There were five animals (e.g., frog, skunk), five foods (e.g., corn, pie), and five people (e.g., old lady, doctor) per book, for a total of 60 items across the four books. A puppet that looked like an alien creature was used to help elicit conversation with the children.

\section{Procedure}

Each dyad came to an on-campus, child-friendly laboratory for two visits (spaced 3-4 weeks apart; mean delay between visits was 24 days). At each visit, the dyad completed three tasks: (a) the parent and the child looked through and discussed a picture book together, (b) the child looked through and discussed a picture book individually with a researcher, and (c) the parent looked through and discussed a picture book individually with a different researcher. Thus, each participant completed four sessions (e.g., the child sessions were as follows: child with parent, Visit 1; child with researcher, Visit 1; child with parent, Visit 2; child with researcher, Visit 2). The parent-child conversation occurred first, followed by both the parent-researcher and child-researcher conversations (which took place simultaneously, in two different testing rooms with two different researchers). Each participant viewed all four picture books across the two visits. Two different books were used for the two parent-child sessions. For the sessions with the researcher, the same book was used for both child-researcher and parent-researcher sessions at a given visit (e.g., for Dyad 1, both parent and child looked through Book B with a researcher at Visit 1 and both parent and child looked through Book D with a researcher at Visit 2). The assignment of books to session and visit was counterbalanced. The order of pages within each book was randomized separately for each dyad, with the constraint that no more than two pages in a row were of the same domain (person, animal, or food).

For the parent-child sessions, parents were asked simply to talk about the book with their child as they normally would at home, and to try to look at every page. For the researcher-child sessions, pilot testing revealed that some children would not talk when simply asked to talk about the pictures. Therefore, to elicit conversation in the childresearcher sessions, the researcher introduced an alien puppet named Zorg, who "doesn't know much" and needed the child's help (see Hollander et al., 2002). The child was directed to talk to the puppet as well as the researcher. The first two pages of the book were practice trials concerning artifacts, and not included in the analyses. For each of the two practice trials, the researcher asked one specific and one generic prompt (e.g., one child would hear: "What can you tell me about this bike?" and "Zorg doesn't know anything about chairs. Can you tell him about chairs?"; another child would hear: "What can you tell me about bikes?" and "Zorg doesn't know anything about this chair. Can you tell him about this chair?"). The first prompt always was a request from the researcher; the second prompt always invoked Zorg as not knowing anything. The order of the practice trials (bike vs. chair) and order of wording (generic first vs. specific first) was fully counterbalanced. The prompts were included to convey that both specific language and generic language were appropriate, and to remind the children that Zorg was ignorant. After the practice trials, neither specific nor generic prompts were used. Each page began with the experimenter asking, "What is this?" (unless the child spontaneously labeled the picture first). The experimenter then provided nondirective, scripted prompts, for example, "What more can you tell me?" "Zorg doesn't know much about this 
one; Can you help him out?" "You can say whatever you'd like." The experimenter aimed to elicit at least two nonlabeling facts about each page, before continuing to the next page. For the parentresearcher sessions, the experimenter asked the parent to just say whatever came to mind when they saw each picture. If the parent asked whether they should talk as if speaking to their child, they were told to talk as they would with another adult. Nondirective, scripted prompts were provided (e.g., "What more can you tell me?" "Can you say a little bit more?"). For each new picture with the child or mother, if the participant did not spontaneously provide a label, the experimenter asked for a label (e.g., "What is this?"). All sessions were videotaped with informed consent.

At the end of Visit 1, parents also completed a brief demographic questionnaire to assess parental age, ethnicity, and educational attainment. At the end of Visit 2, children were administered the Peabody Picture Vocabulary Test (PPVT) to assess their vocabulary, and standard scores were calculated. At the same time, parents completed an essentialism questionnaire to assess the extent to which they construe various trait categories as stable, immutable, and richly structured (adapted from Gelman, Heyman, \& Legare, 2007). The essentialism questionnaire focused on 20 traits (anxious, artistic, athletic, cautious, feminine, goal-oriented, having a good sense of direction, humorous, intelligent, masculine, mathematically talented, messy, musically talented, neat, nurturing, outgoing, pessimistic, responsible, shy, and stubborn). For each, we assessed seven dimensions of essentialist reasoning (listed in the Appendix, using "shy" as the sample characteristic).

\section{Results}

\section{Coding}

All sessions were transcribed verbatim from the video recordings and checked by a second transcriber. Utterance breaks were determined by the presence of a new subject noun phrase. Thus, "Does he like to live where it's cold or hot?" constituted a single utterance, whereas, "Does he live in the water or does he live on the ground?" was split into two utterances ("Does he live in the water?" "Or does he live on the ground?").

Coding proceeded in two waves. The first wave included four steps. First, each utterance was coded as intelligible or unintelligible. Utterances were counted as unintelligible if all or most of the content was inaudible; $99 \%$ of utterances were intelligible. Second, intelligible utterances were coded as on or off task; $89 \%$ of intelligible utterances were on task. Off-task utterances were not related in any way to the picture, or to the conversation prompted by the picture. For example, any procedural discussion (e.g., "Two more pages after this") was coded as off task. In contrast, comments about the content of the pictures in the book were coded as on task (e.g., "What is the next one?"). Third, on-task utterances were coded as either containing a noun or pronoun, or not. Finally, on-task utterances containing a noun or pronoun were coded as generic or nongeneric, using criteria developed in prior research (Gelman et al., 1998; Gelman et al., 2004). Generic utterances by definition required a noun phrase, and included reference to a category in general. Sample child utterances that were coded as generic include: "And sharks could eat dolphins"; "A grandma comes to visit you a lot"; "Race cars go really fast." Sample child utterances that were coded as nongeneric include: "And the fireman rescued the lady"; "I have a lot of fire alarms in my house"; "This is a broccoli." Table 1 provides more examples.

Table 1

Study 1, Sample Generic and Nongeneric Utterances Produced by Children (With Subject Number in Parentheses)

\section{Generic}

You can eat popcorn. (11)

They're [witches] pretend. (16)

Cats have sharp claws and are family to a lion. (22)

Ducks float on water. (23)

I love butterflies. (34)

And Morg [sic], penguins flap their wings. (42)

You eat pretzels. (44)

I mean, I don't like skunks. (49)

Um and turtles are creatures that crawl in hot places like the desert. (56)

Yeah, it [alligator] eats people. (57)

Crackers go in soup. (64)

A frog usually hops, all day long. (72)

Nongeneric

He needs a helmet if the football hits her [sic]. (11)

Oh Mommy, this is so cute. (16)

Zorg, this is a cat. (22)

Short legs, little head, black spots. [ladybug] (23)

He's a judge. (34)

Ew, look at its [ladybug's] face. (42)

It's yellow. (44)

He is big and strong. (49)

I have a puppy. (child 56)

A birdie. [penguin] (57)

A ballerina. (child 64)

A banana. (72) 
A second wave of coding was conducted to provide a more conservative coding of generics. Specifically, those utterances in which the only generic was a pronoun that can be loosely translated as "one" (typically "you" or "we"; e.g., "We call it yellow"; "This is a cracker that you eat") were recoded as nongeneric. We recoded such utterances because they may be indefinite (akin to "someone") rather than generic. Altogether, $10.8 \%$ of utterances that had been coded as generic in Wave 1 were recoded as nongeneric in Wave 2.

To determine interrater reliability, all transcripts that had not been used for training purposes were coded by two independent raters. Disagreements were resolved by discussion. We report interrater reliability for each of the two coding waves separately. For Wave 1, interrater reliability was calculated on $N=62$ transcripts from the motherchild context at Visit 1, N=63 transcripts from the researcher-child context at Visit 1 , and $N=72$ for all other pairings of context and visit. The Wave 1 agreement and kappas were as follows: intelligibility agreement $=99.7 \%$, intelligibility kappas $=.88$; on-task agreement $=97 \%$, on-task kappas $=.87$; noun phrase agreement $=98 \%$, noun phrase kappas $=.95 ;$ generic agreement $=94 \%$, generic kappas $=.83$. Because Wave 2 only involved the coding of generics, interrater reliability for Wave 2 is reported for generic coding only $(N=67)$ : agreement $=99 \%$, kappas $=.96$. All the kappas fall within near-perfect (.81 and above) levels (Landis \& Koch, 1977).

\section{Generic Production Scores}

So that individual differences were not confounded by speaker's overall talkativeness, our measures of generic production were not raw scores of generic frequency, but rather the number of generics divided by the number of on-task utterances. However, it was also important to ensure that rates of generic production were not simply a reflection of participants' rate of producing nouns or pronouns. Participants differed in how frequently they produced responses without a noun or pronoun (e.g., "Yes," "OK," "Right"), and we wished to make sure that differences in rates of generic production could not be attributed to such stylistic differences. To test this, we examined two different ways of computing generic production scores: (a) number of generics divided by the number of all on-task utterances versus (b) number of generics divided by the number of all on-task utterances including a noun or pronoun. We calculated each of these scores separately for mothers and children within each context and visit. We then examined the correlations between the two scoring methods for each combination of participant, context, and visit, resulting in eight correlations. The results showed that these two methods correlated extremely highly, with Pearson correlations ranging from $r \mathrm{~s}(70)=.94-.99, p s<.001$. Thus, calculating a generic production score using on-task utterances as the denominator provides an accurate estimate of generic rate and does not reflect "noun-iness" per se.

Using this method, we computed four generic production scores for each participant within each book-reading event: (a) the number of generics on the animal pages divided by the number of on-task utterances on the animal pages, (b) the number of generics on the food pages divided by the number of on-task utterances on the food pages, (c) the number of generics on the person pages divided by the number of on-task utterances on the person pages, and (d) the total number of generics divided by the total number of on-task utterances.

Because each speaker participated in four bookviewing sessions across the two visits (parent-child Visit 1, parent-child Visit 2, participant-researcher Visit 1, participant-researcher Visit 2), there were 32 generic production scores per dyad: 2 (speakers) $\times 4$ (sessions) $\times 4$ (scores). These data were analyzed to examine frequency of generics, individual consistency, and which nonlinguistic factors predict generic production.

\section{Frequency of Generics}

Before turning to the analyses investigating individual consistency, we provide a descriptive portrait of the rate of generic production across contexts, visits, speakers, and domains. We conducted an analysis of variance (ANOVA) on the proportion of generic utterances, with laboratory visit (first, second), context (speaking with each other or with a researcher), and domains (people, animals, food) as within-subject variables, and speaker (parent, child) as a between-subject variable. Both children and parents produced significantly more generics when speaking with the researcher than with each other (see Figure 1), $F(1$, 142) $=74.29, p<.001, \eta_{p}^{2}=.34$. This context effect may reflect the greater shared experiences of the parent and child, which tend to be specific. For example, parent-child dyads often reminisced about a particular event (e.g., "Hey yeah, we got you a turtle last year at the flower place, remember?"). In contrast, participants had no such shared 


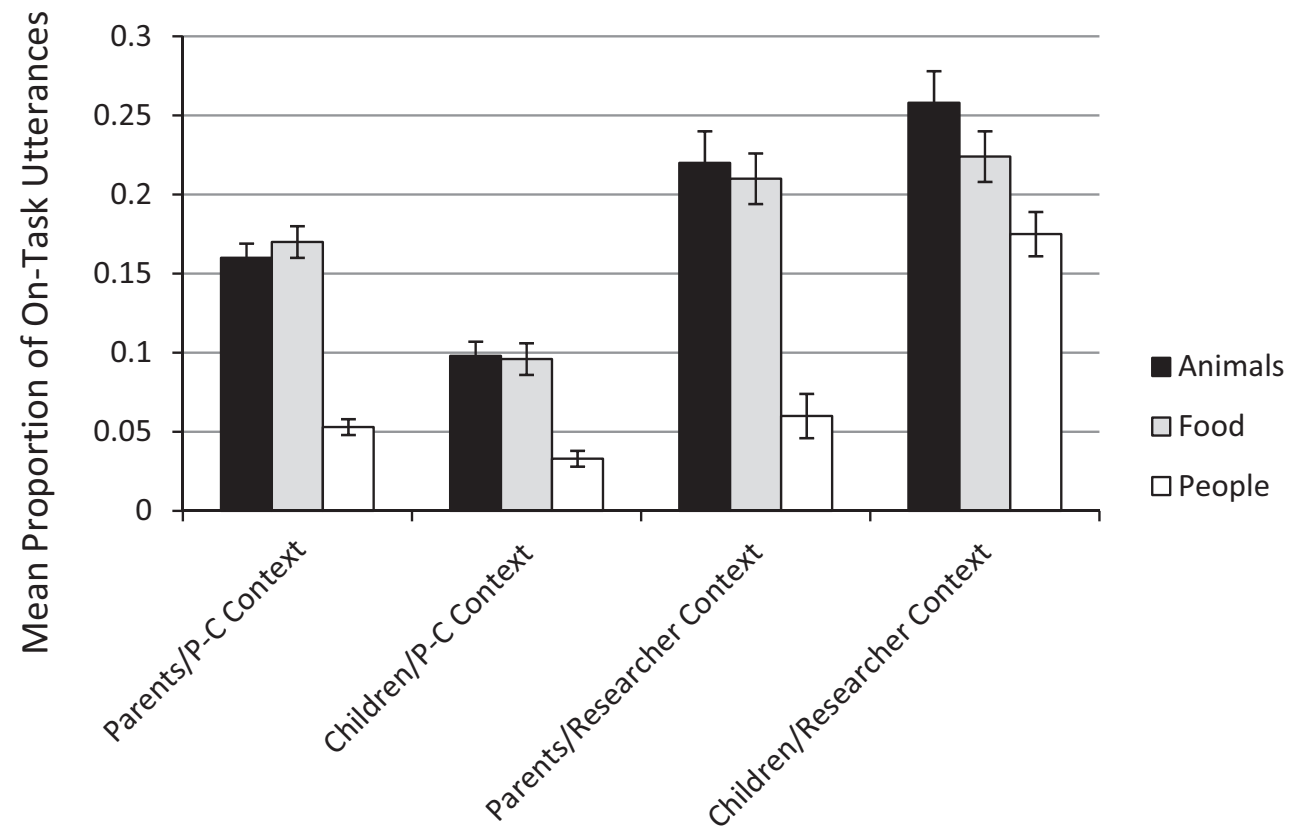

Figure 1. Study 1, mean proportion of on-task utterances that included a generic, produced by parent and children when speaking to each other and when speaking to a researcher, by domain. P-C = parents-children.

context with the researcher, and thus may have been less likely to discuss specific contexts and more likely to refer to general knowledge. Interestingly, there was also a significant interaction between speaker and context, $F(1,142)=26.23$, $p<.001, \eta_{p}^{2}=.16$. Although parents produced more generics than children in the parent-child conversations, $p<.001$, children produced more generics than parents when speaking with a researcher, $p=.01$. In the Discussion, we interpret these effects as reflecting a tendency to produce more generics within pedagogical than nonpedagogical contexts (see also Gelman et al., 2013). Whereas parents assumed a pedagogical role when speaking with their children, given the greater expertise of the parents, children assumed a pedagogical role when speaking with the researcher because they were encouraged to provide information for the alien puppet who knew very little.

The remaining significant effects involved domain. Generics were much more frequent regarding animals and food than people $(.18, .17$, and .08 , respectively), $F(2,284)=191.46, p<.001, \eta_{p}^{2}=.57$ ( $p s<.001$ for the pairwise comparisons involving people; $p>.12$ for the pairwise comparison of animals and food). However, domain interacted with speaker, $F(2,284)=22.32, p<.001, \eta_{p}^{2}=.14$. Whereas generics about animals and food were produced at fairly equivalent rates by parents and children (animals: .19 and .18, respectively, $p>.5$; food: .19 and .16, respectively, $p=.056$ ), children were more likely to produce generics about people than were their parents $(.10$ and .06 , respectively, $p=.011)$. This unexpected result may suggest greater essentialism on the part of children (Taylor, Rhodes, \& Gelman, 2009), or a tendency on the part of parents to avoid talking about types of people, perhaps judging this to be potentially rude or offensive. Finally, domain interacted with context, $F(2,284)=7.01, p=.001, \eta_{p}^{2}=.05$. Although animals and food elicited more generics than people in both the mother-child and researcher context, there was a slight tendency for speakers to produce more generics about animals than food in the researcher context only $(M s=.24$ and .22 , respectively, $p<.01$ ).

There were no other significant effects, including no significant effects of visit, $F(1,142)<1.0$. Accordingly, we collapsed over visit in the correlational analyses reported below.

\section{Individual Consistency}

We conducted Pearson correlations to examine consistency in generic production across time, contexts, and domains. As shown in Table 2, all 18 of these correlations were positive, and 17 of 18 reached statistical significance. The analysis of consistency over time examined the correlation between the rate of generic production on the first 
Table 2

Study 1, Pearson Correlations Examining Consistency Over Time, Contexts, and Domains (All dfs $=70)$

\begin{tabular}{lll}
\hline & Parents & Children \\
\hline Consistency over time & & \\
Visit $1 \sim$ Visit 2 (researcher context) & $.75^{* * *}$ & $.69^{* * *}$ \\
Visit $1 \sim$ Visit 2 (parent-child context) & $.35^{* *}$ & .16 \\
Consistency over context & & \\
Parent-child $\sim$ Researcher contexts & $.36^{* *}$ & $.25^{*}$ \\
Consistency over domain & & \\
Animal $\sim$ People (researcher context) & $.62^{* * *}$ & $.82^{* * *}$ \\
Animal $\sim$ Food (researcher context) & $.76^{* * *}$ & $.80^{* * *}$ \\
People $\sim$ Food (researcher context) & $.55^{* * *}$ & $.75^{* * *}$ \\
Animal $\sim$ People (parent-child context) & $.53^{* * *}$ & $.35^{* *}$ \\
Animal $\sim$ Food (parent-child context) & $.47^{* * *}$ & $.39^{* *}$ \\
People $\sim$ Food (parent-child context) & $.29^{*}$ & $.24^{*}$ \\
\hline
\end{tabular}

${ }^{*} p<.05 .{ }^{* *} p<.01 .{ }^{* * *} p<.001$.

laboratory visit with the rate of generic production on the second laboratory visit, for parents and children separately within each conversational context (parent-child and researcher). Both parents and children were highly consistent across visits when speaking with a researcher. Consistency across visits was lower for the parent-child context, although it was significantly positive for parents. The analysis of consistency over context examined the correlation between the rate of generic production in the parent-child context with the rate of generic production in the researcher context, for parents and children separately. Both parents and children displayed consistency whether speaking with a family member or a researcher. Finally, the analysis of consistency over domain examined the correlation between the rate of generic production for animals, people, and food with one another, for parents and children separately within each conversational context (parent-child and researcher). Correlations were consistently high across domains, particularly for the researcher context.

In addition, we examined consistency across speakers (within dyads), separately for each context. Within the parent-child context, correlations between parents and children were high, $r(70)=.63$, $p<.001$. However, within the researcher context, there was no significant correlation between parents and children, $r(70)=.05, p>.60$.

\section{Relation of Nonlinguistic Factors to Generic Production}

In this last set of analyses, we examined whether rate of generic usage related to other factors, such as child age, child vocabulary, or parent education.
If so, it would be important to determine if the correlations examined above obtain when the relevant factors are controlled. Child age and parent education displayed no significant relation with generic production of either parent or child in either the parent-child or the researcher context, $p$ s $>.40$. PPVT standard scores were also not significantly related to generic production, although the correlation approached significance with children's generics in the researcher context, $r(70)=.23, p=.053$. We therefore conducted partial correlations for all the analyses in the Individual Consistency section, controlling for PPVT score. All the significant effects remained significant, with one exception: the correlation between children's generics in the parent-child context and children's generics in the researcher contexts reduced slightly, to $r(69)=.22$, $p=.068$.

We next examined whether rate of generic usage corresponds to parental essentialism. We assessed seven aspects of essentialism: stability over time, innate predisposition, inheritance from birth parent, genetic basis, detectability in babies, resistance to environmental influence, and resistance to change. We calculated separate correlations for each of these dimensions. Six of the seven dimensions showed no significant relations to generic production; however, the dimension of stability consistently correlated with generic production rates, for both children-r(70) $=.27$ in parent-child context, $p<.05 ; r(70)=.35$ in researcher context, $p<.01-$ and parents- $r(70)=.24$ in parent-child context, $p<.05 ; r(70)=.21$ in researcher context, $p<.10$. In other words, parents who judged traits to be more stable and unchanging over time produced generics at a higher rate and had children who produced generics at a higher rate. Overall, parents tended toward the essentialist end of this scale assessing stability, with scores on a scale of 1-6 (averaged over the 20 traits) ranging from 3.6 (indicating a slight tendency for traits to be stable over time) to 5.9 (indicating almost complete stability for every trait).

\section{Discussion}

Study 1 revealed stable individual differences in the tendency to produce generic language. The rate at which speakers produced generics was highly consistent over time (from Visit 1 to Visit 2), over contexts (parent-child conversations vs. conversations with a researcher), over domains (animals, people, and food), and within dyads (parents who produced relatively more generics had children 
who produced relatively more generics). Furthermore, these differences correlated with parents' beliefs about the stability of categories over time, which is one component of essentialist reasoning. Although we cannot draw conclusions about causality from correlational evidence, these findings suggest that adults' rate of generic language production may reflect conceptual differences in essentialism.

One limitation of Study 1 is that all the contexts involved looking through picture books with a similar structure. The consistency of context had the advantage of ensuring that individual differences cannot be due to variations in selected activity or content. However, this controlled, unvarying, highly pedagogical activity may have prompted greater consistency and thus inflated the cross-context correlations. Perhaps cross-context consistency would not occur if the contexts differed from one another in the kinds of interaction they afford. We conducted Study 2 to address this question. Specifically, we systematically varied the pedagogical nature of the interactional contexts by examining parent-child conversations in both a picture examination context and a toy play context. Children were drawn from two different age groups to examine these patterns over development.

\section{Study 2}

Study 2 examined consistency of generics across two distinct interactional contexts: looking at pictures and playing with toys. Looking at pictures is assumed to be a more pedagogical context than playing with toys. Pictures are often presented in a book-reading context, and are treated as representations (Gelman et al., 2005). In contrast, toys elicit more focus on the affordances of the item as an individual object. Parents and children use more noun phrases and more generics when looking at pictures versus playing with toys, and more verbs and a greater focus on individuating phrases when playing with toys than looking at pictures (Gelman \& Tardif, 1998; Gelman et al., 2005; Tardif, Gelman, $\& \mathrm{Xu}, 1999)$. Interactions with toys are also more playful than interactions with pictures (e.g., during toy play, participants more often talk to the item or give it a proper name; Gelman et al., 2005).

Study 2 was a secondary analysis of data that had previously been gathered for a project on parent-child talk about conceptual relations (e.g., taxonomic, thematic) as a function of representational medium (pictures vs. objects; Ware, Gelman, \&
Kleinberg, 2013). Although the prior project did not include coding of generics, the data set is well suited to the questions posed in this study. Participants were parent-child dyads, with conversations in two different interactional contexts in which all dyads received the same setting and basic informational content (animals, food, artifacts). The data set allows us to examine consistency within dyads, across contexts, and across domains. To the extent that consistency is obtained, it cannot be due to individual variation in context or topic, given the controlled settings.

Importantly, the previously published report showed clear differences between the picture context and the object context in interactional patterns, suggesting that these contexts are distinct in their pedagogical nature. Pictures elicited more taxonomic relations (e.g., indicating that different items are animals) and shared property relations (e.g., indicating that a pear and corn are both healthy), whereas objects elicited more thematic relations (e.g., indicating that a hammer could be used to pound on a watermelon) and slot-filler relations (e.g., indicating that a fish eats ice cream and an elephant eats ice cream). Pictures also tended to elicit more conventional relations than objects, which elicited more playful and unconventional relations.

In Study 2, we recoded these parent-child interactions with regard to generic language, as well as the domain content of each generic (as animal, food, artifact, or other). These data were then analyzed to determine the consistency of individual differences in generic usage.

\section{Method}

\section{Participants}

Participants were 2-year-olds $(N=16 ; 8$ boys, 8 girls; mean age $=2.9$; range $=2.5-3.1)$, 4-year-olds $(N=16$; 8 boys, 8 girls; mean age $=4.3$; range $=$ 3.7-5.0), and their parents $(N=32$; all females). All participants were White. An additional four dyads were tested but not included (two failed to complete the task, one spoke non-English, and one was unintelligible).

\section{Materials}

Each dyad received items in two blocks (pictures, toys), in counterbalanced order. The toys were small replica objects. Each picture was a laminated card depicting a color, realistic drawing of one of the toys. There were 12 pictures and 12 toys per 
dyad, equally divided among animals, foods, and artifacts (Ware et al., 2013). Thus, each dyad received one block containing four pictures of animals, four pictures of foods, and four pictures of artifacts, and another block containing four toy animals, four toy foods, and four toy artifacts. Within a dyad, the pictures and toys represented 24 different categories, but across dyads, each category was presented as a picture for half the participants and as a toy for half the participants, matched in appearance (e.g., half the dyads saw a toy elephant, whereas half saw a drawing of the same toy elephant). The animals included cow, crab, eagle, elephant, fish, frog, lion, and pig; the food included corn, French fries, hotdog, ice cream, lemon, pear, pizza, and watermelon; and the artifacts included airplane, couch, hammer, house, piano, shoe, table, and truck.

\section{Procedure}

Parent-child dyads were brought to a childfriendly laboratory at a university and video recorded while interacting with one another in two back-to-back, counterbalanced sessions. One session involved looking through a set of 12 cards; the other involved playing with a set of 12 objects (see Materials, above). Participants were instructed to play as they normally did at home, but were asked to spend time with each item. The dyads with 2year-olds were given 8 min per session; the dyads with 4-year-olds were given $10 \mathrm{~min}$ per session.

\section{Results}

\section{Coding}

Coding was conducted from transcriptions prepared for the previous project (Ware et al., 2013). First, each utterance was coded as either on task and intelligible or off task (including unintelligible); $89 \%$ of utterances were intelligible and on task. Second, every on-task utterance was coded as generic or nongeneric, using the criteria from the second wave of Study 1. Third, every generic utterance was coded for domain (animal, food, artifact, or other). Nongeneric utterances were not coded for domain because such lines often were ambiguous as to domain, given that items from multiple domains were simultaneously available to participants.

Two independent raters coded a subset of transcripts, with disagreements resolved by discussion. For generic coding, agreement $(N=28$ transcripts) was $99 \%$ and kappa was .91. For content coding, agreement ( $N=16$ transcripts, 1 context each) was 97\% and kappa was .93. All the kappas are within near-perfect levels (Landis \& Koch, 1977).

\section{Frequency of Generics}

We computed four generic production scores for each participant within each context (pictures vs. toys): (a) the number of generics regarding animals divided by the total number of on-task utterances, (b) the number of generics regarding food divided by the total number of on-task utterances, (c) the number of generics regarding artifacts divided by the total number of on-task utterances, and (d) the total number of generics divided by the total number of on-task utterances. For each domain, the generic production scores were divided by the total number of on-task utterances (rather than the number of on-task utterances for that domain, as in Study 1) because domain was coded for generics only.

To assess the rate of generic production across contexts, speakers, and domains, we conducted an ANOVA on the proportion of generic utterances, with context (pictures vs. toys) and domain (people, animals, food) as within-subject variables, and speaker (parent, child) and age group (2- and 4year-olds) as between-subject variables (see Figure 2). An initial analysis revealed no significant effects involving block order, so that factor was excluded from further analyses. Parents produced more generics than children $(M s=.022$ and .01 , respectively), $F(1,60)=16.15, p<.001, \eta_{p}^{2}=.21$. Pictures elicited more generics than objects (Ms $=.018$ and .013 , respectively). $F(1,60)=6.26$, $p=.015, \eta_{p}^{2}=.09$. There was also a main effect of domain, $F(2,120)=18.64, p<.001, \eta_{p}^{2}=.24$. Post hoc comparisons revealed that generics were more frequent for animals $(M=.021)$ and food $(M=.021)$ than for artifacts $(M=.006)$, $p$ s $<.001$, with no differences between animals and food. Finally, there was a Context $\times$ Domain interaction, $F(2,120)=$ 3.84, $p=.024, \eta_{p}^{2}=.06$. The generic advantage for pictures over objects was significantly maintained in both the food and artifact domains, $p$ s $<.05$, but not in the animal domain, where generics were consistently high in both contexts.

\section{Individual Consistency}

We conducted partial Pearson correlations, controlling for age, to examine consistency in the production of generics across contexts and domains 


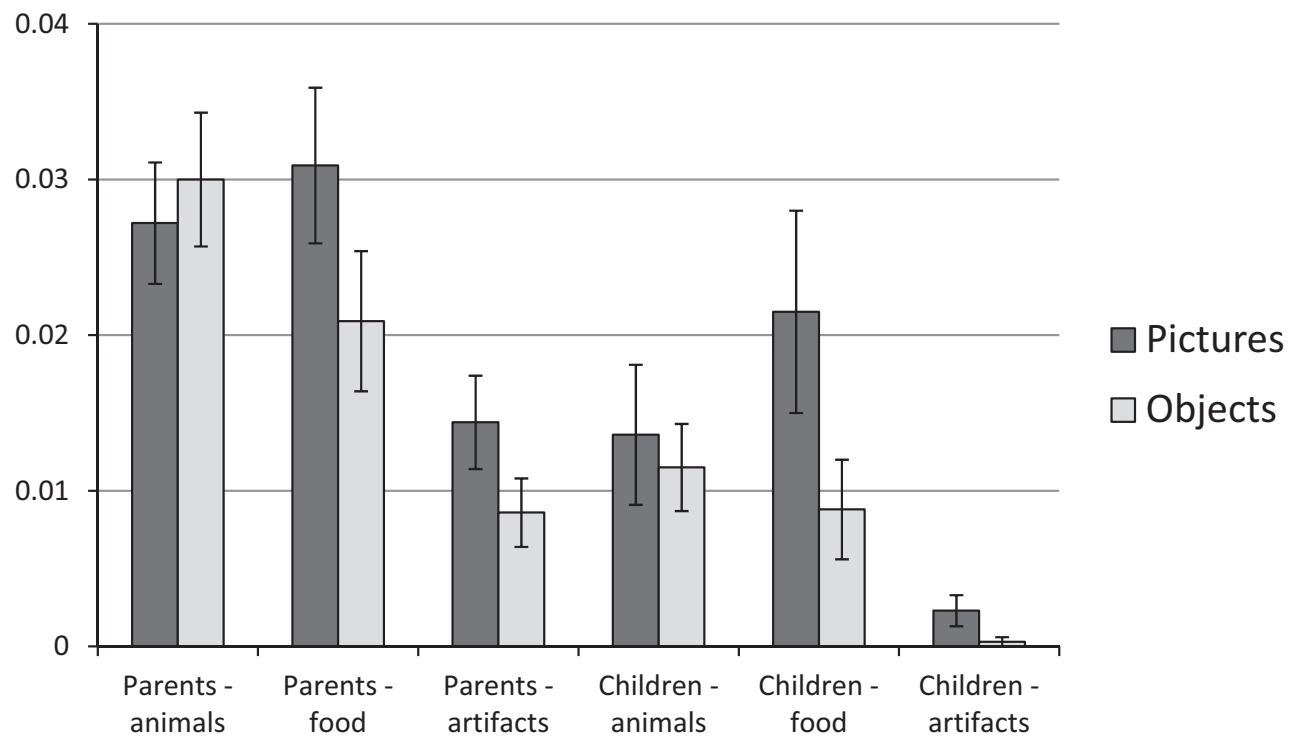

Figure 2. Study 2, mean proportion of on-task utterances that included a generic, produced by parent and children when looking at pictures and when playing with toys, by domain.

Table 3

Study 2, Pearson Correlations Examining Consistency Over Time, Contexts, and Domains, Partialing Out Age (All dfs = 29)

\begin{tabular}{lcc}
\hline & Parents & Children \\
\hline Consistency over context & & \\
$\quad$ Pictures Toys & $.30^{*}$ & $.66^{* * *}$ \\
Consistency over domain & & \\
Animal $\sim$ Food (picture context) & $.44^{*}$ & $.48^{* *}$ \\
Animal $\sim$ Artifact (picture context) & .21 & .12 \\
Food $\sim$ Artifact (picture context) & .03 & -.00 \\
Animal Food (toy context) & -.02 & .04 \\
Animal $\sim$ Artifact (toy context) & .27 & -.16 \\
Food $\sim$ Artifact (toy context) & $.40^{*}$ & $.68^{* * *}$ \\
\hline
\end{tabular}

$* p<.05$, one tailed. $* * p<.01 . * * * p .001$.

(Table 3). The analysis of consistency over context examined the correlation between the rate of generic production in the picture context with the rate of generic production in the toy context, for parents and children separately. Both parents and children displayed consistency over context. The analysis of consistency over domain examined the correlation between the rate of generic production for animals, food, and artifacts with one another, for parents and children separately within each conversational context (picture and toy). Correlations were significantly positive across certain domains, although they differed across contexts. With pictures, significant correlations were obtained when comparing animal and food generics, for both children and parents. In contrast, with toys, significant correlations were obtained when comparing food and artifacts, for both children and parents.

We also examined consistency across speakers, separately for each context, again controlling for age. Within both the picture and the toy contexts, correlations between parents and children were high: for pictures, $r(29)=.63, p<.001$; for toys, $r(29)=.54, p<.01$.

\section{Discussion}

Study 2 replicated several findings of Study 1, including consistency over contexts, within dyads, and over some domains. Most notably, participants were consistent across contexts, even though the contexts were more varied in Study 2 than in Study 1. The picture context was more pedagogical, eliciting more generics, more talk about taxonomic relations, more shared property relations, and more conventional relations. In contrast, the object play context was more nonpedagogical, eliciting fewer generics, more talk about thematic links, more slotfiller relations, and more unconventional relations. Informal impressions confirmed that the picture context elicited more pedagogical interactions (e.g., participants declared search rules, such as finding pictures that matched on a certain dimension), whereas the object context elicited more playful interactions (e.g., speaking for the animals, or engaging in pretense). Nonetheless, children and mothers who produced relatively more generics in 
one context also did so in the other context. Thus, the consistency over contexts obtained in Study 1 was not solely due to the fact that the contexts were so similar (a book-reading task).

Also as in Study 1, we found that children and mothers were highly consistent with one another. Thus, dyads where mothers produced many generics tended to be those where children produced many generics. However, we cannot determine from Study 2 whether this consistency is due to factors present within the conversation (e.g., parents and children focusing on common topics) or to a more general correspondence between the language of parents and their children.

We also examined consistency across domains in this study. Here, we obtained some findings that mirrored those of Study 1, as well as some findings that did not. As in Study 1, the tendency to produce generics in one domain was not wholly independent of the tendency to produce generics in other domains. It thus cannot be that high levels of generics strictly reflect expertise or interest in a particular domain. However, only 4 of the 12 crossdomain correlations were significant in Study 2 (as compared to all the cross-domain correlations in Study 1). In part this may reflect lower statistical power, due to a smaller $N$ and the inclusion of just one visit instead of two. However, another possibility is that the differences in how we computed the domain-specific generic scores were responsible for the differences. Recall that in Study 1, scores were computed wholly within domain (e.g., the number of generic utterances regarding animals divided by the number of total utterances regarding animals), whereas in Study 2, the scores were not computed wholly within domain (e.g., the number of generic utterances regarding animals divided by the number of total utterances across all domains). This change in Study 2 was necessitated by the fact that many utterances referred to multiple domains, or to no one clear domain. However, it resulted in a less sensitive measure than in Study 1, which may have contributed to the null findings. In any case, for those correlations that are significant, we find a positive relation in frequency of generics across domains, for children and parents.

\section{General Discussion}

These studies reveal marked variation in how often children and parents talk about categories as opposed to particular instances. Each individual saw the same items and received the same prompts, thus controlling for context and content. Sometimes speakers described particular items at hand (e.g., "Is that a baby horsie or a big horsie?"), sometimes speakers reminisced about prior events in their lives (e.g., "Oh, remember when we passed that elephant at the zoo?"), and sometimes - of greatest interest to the current investigation-speakers used the pictures or objects as a jumping-off point to talk about the categories they represented using generic noun phrases (e.g., "And where do frogs live?"). How often people Spontaneously evoked generics varied considerably: Some people never produced a single generic, whereas others produced generics on nearly two thirds of their utterances.

Our primary question is whether variation in generic production reflects stable individual differences. In other words, are some people consistently more focused on generic kinds than others? One possibility is that there is no consistency. The use of generics could be highly variable, reflecting shifts in a person's attention or recent experiences. Similarly, a person who produces a high rate of generics about a category for which he or she has special interest or knowledge may be highly specific about other categories. We already know that rate of generics reflects content (more generics regarding animals than artifacts; Brandone \& Gelman, 2009) and context (picture books eliciting more generics than toys; Gelman et al., 2005).

However, the current findings show stable individual differences in how likely a person is to talk about generic categories. All three measures of stability (time, context, and domain) show consistency, for both children and their parents. First, in Study 1 both parents and children exhibited consistency across the two visits, 3-4 weeks apart. Parents were highly consistent whether speaking with a researcher or speaking with their child. Children also displayed strong consistency across visits when talking with a researcher, although not when talking with a parent. Recall that the researcher provided only neutral and minimal prompts (e.g., "Can you tell me more?"), which may have reduced contextual pulls toward particular topics and thus increased consistency. In any case, although the content of the particular books differed across visits, the rate of generic production was highly predictable over time.

Second, participants showed consistency across two contexts. In Study 1, the contexts were speaking with a family member (in a parent-child dyad) and speaking with a researcher. For both parents and children, although the level of generic production varied across contexts, those who produced 
more generics in one context tended to produce more generics in another context. Thus, whether talking with a family member who knows you well, has a shared history, and is contributing richly to the conversation, or talking with a relative stranger who provides a scripted interaction with minimal cues, rate of generic language is fairly stable. Similarly, in Study 2, parents and children were highly consistent in their generic production across a pedagogical context (looking through pictures) and a nonpedagogical context (playing with toys). The cross-context consistency in Study 2 was particularly striking, given that the two contexts elicited markedly different kinds of language (more pedagogical, generic, taxonomic, and conventional language in the picture context compared to the toy context).

Third, participants exhibited some consistency in their generic production across domains, although this differed by study. In Study 1, we assessed cross-domain consistency by varying the content of the pages in the picture books. Although speakers were much more likely to produce generics regarding animals and food than people, relative rates of generic language production were highly stable across domains (e.g., those who were more generic about animals tended to be more generic about foods and people). Again, this stability held true for both parents and their young children. In Study 2, we assessed cross-domain consistency by varying the content of pictures and toys. Generics were more frequent about animals and foods than artifacts, replicating prior research (e.g., Gelman et al., 1998). Moreover, both parents and children showed some consistency across domains, although this finding was variable (i.e., there were no significant cross-domain correlations involving artifact pictures or animal toys).

Given these findings, a key question is why some people produce generics more than others. Rate of generic production cannot be attributed to talkativeness (as the dependent measures controlled for the amount of talk) or tendency to produce nouns (as rates of generic production in Study 1 are nearly identical when one restricts the analysis to only utterances containing nouns). However, a variety of other factors may contribute to speakers' tendency to use generics, including their view that categories are an important or interesting topic of conversation (perhaps influenced by their motivation to engage in pedagogical interactions), their history with hearing generic language in the past, or stylistic speech preferences. For example, just as certain speakers demonstrate preferences for ques- tions, imperatives, adverbs, or fillers, there may be a linguistic preference for generics. The stability estimates might also be influenced by more general priming factors, such as syntactic priming (Gelman \& Raman, 2007; Shimpi, Gámez, Huttenlocher, \& Vasilyeva, 2007) or contextual priming (e.g., due to the conversations all taking place in a laboratory setting).

We also investigated whether generic production reflects conceptual attitudes, given that other features of spontaneous language production have been shown to reflect important conceptual attitudes. For example, a speaker's use of pronouns, prepositions, and articles predicts important personal characteristics, such as personality, confidence, truthfulness, or romantic compatibility (Pennebaker, 2011). Indeed, we found that variation in generic language reflects differences in one aspect of essentialism. Study 1 examined parents' essentialist beliefs about a range of 20 personal traits, using a questionnaire task. Traits were included because they evoke more varied beliefs than animal categories (e.g., adults differ substantially in the extent to which they believe that intelligence is inborn and fixed; Dweck, 2006; Rhodes \& Gelman, 2009; Taylor et al., 2009). The questionnaire measured seven dimensions of essentialist reasoning, ranging from beliefs that traits can be discerned by genetic testing, to beliefs that traits cannot change as a function of desires. Results indicated that parents who held the belief that trait categories are stable over time were more likely to produce generics. None of the other measures of essentialism correlated with generic language. However, it is perhaps not surprising that stability was the one dimension that was predictive. Generics imply that a predicate is general, obtains across contexts, and is broadly generalizable. In other words, generics imply that a predicate is stable. Interestingly, this finding parallels Heyman and Diesendruck's (2002) result that Spanish-speaking children with stable views of traits are more likely to use "ser" (the more "permanent" form of the verb "to be"). Generics may not imply other dimensions of essentialism, such as that a predicate is fixed at birth or genetically determined.

The finding that generic production is linked to conceptual beliefs is consistent with the interpretation that generics are not just a way of talking, but instead reflect a conceptual attitude (see also Rhodes et al., 2012). Some people seem to be more likely to think about the world as consisting of stable categories, and this way of thinking is reflected in their language use. We speculate that this 
perspective is domain general, such that speakers who are relatively more essentialist about one domain are relatively more essentialist about other domains as well (although the absolute level of essentialism will vary across domains). Although this idea has not been directly tested with the domains of animals, food, and artifacts, prior research does show that essentialism of different human characteristics is highly intercorrelated (e.g., someone who is relatively more essentialist about musical skill is also relatively more essentialist about shyness; Gelman et al., 2007). It would be valuable in future research to examine whether those who view categories as more stable over time have other aspects of their personality, attitudes, or cognitive style that might predict this dimension. For example, adults who are more essentialist may be more conservative toward a range of activities and behaviors (Jost, Glaser, Kruglanski, \& Sulloway, 2003; Rhodes \& Gelman, 2009), or be more likely to endorse the idea that environmental regularities are inherent and stable (Cimpian \& Salomon, in press).

A further important point is that parental beliefs and language relate systematically to children's language. We see this relation in two ways. First, in both studies, generic language in parents correlates highly with generic language in children-although only when parent and child are in conversation with each other. When parent and child are talking to researchers, this tight link between their modes of speaking disappears. This may imply that the correlation between parent and child generics in the parent-child conversations reflects processes that are ongoing in the moment, such as nonconscious conversational alignment strategies, whereby a speaker implicitly mirrors the speech patterns of the person they are talking to (Niederhoffer \& Pennebaker, 2002; Pickering \& Garrod, 2004). It remains currently unclear whether the tight link between parent and child generics during parent-child conversation is merely a transitory phenomenon, or whether it may ultimately have longer term implications for how frequently children focus on generic kinds. Consistent with the latter possibility, prior studies have demonstrated important and enduring relations between parental speech and children's own language development (Hart \& Risley, 1995; Hoff, 2006; Huttenlocher, Waterfall, Vasilyeva, Vevea, \& Hedges, 2010; Naigles, 2000). However, whether these relations hold up at the level of generic language remains an open issue for future research.

Second, and perhaps more important, Study 1 found that parents who more firmly believe that traits are stable over time have children who more frequently produce generics. A critically important question for the future concerns the mechanism by which child and parent beliefs and generic language interrelate (see Segall \& Diesendruck, 2013). Perhaps parents and children hold similar essentialist beliefs, which are reflected in similar levels of generic language. Alternatively, parental generic language may influence children's essentialist reasoning (see Gunderson et al., 2013, for an example of how parental praise can affect children's motivational frameworks several years later). Other patterns are possible as well (e.g., children may simply be mimicking the style of language that they hear from parents). Regardless of whether concepts are driving language, or language is driving concepts, the data provide evidence for intergenerational transmission of parental beliefs.

Although our primary focus was on individual differences, it is also notable that when examining the Study 1 data, we obtained an interaction between speaker (parent, child) and context (parent-child, researcher). Specifically, in the parentchild context, parents provided more generics than children, whereas in the researcher context, children provided more generics than parents. We hypothesize that these patterns are a direct consequence of the pedagogical status of children and parents in the two contexts. Pedagogical contexts promote generic language (Study 2 of this article; Gelman et al., 2013; see also Csibra \& Gergely, 2009). For example, informational books include substantially more generics than narrative books, book reading evokes more generics than toy play, and both children and adults produce more generics when pretending to be a teacher than when pretending to be a younger child. The finding that parents produce more generics than children in the parentchild context can be predicted from parents' role as the more knowledgeable speaker in that context. In contrast, the finding that children produce more generics than parents in the researcher context of Study 1 may reflect that the children's task was pedagogical in nature (teaching an ignorant puppet about the items in the book), whereas the parents' was nonpedagogical (chatting with the adult researcher).

It is also striking that children produced so many generics, in some cases far exceeding their parents. This result suggests that young children may be especially focused on kinds, as other researchers have suggested in the domain of gender (Trautner et al., 2005). It would be interesting, in future research, to attempt to control for pedagogical 
status and assess the frequency of generic talk over development, from early childhood through to adulthood. In the early preschool years, children often express generics that seem gratuitous: "Adams don't have to take naps!" (said by a 2.5year-old named Adam); "Houses don't have legs" (said by a 3-year-old). Perhaps preschoolers are more likely to see the world in terms of categories, and their language reflects this perspective. This possibility would be consistent with work finding relations between early category knowledge and language skills (Beckage, Smith, \& Hills, 2011; Borovsky \& Elman, 2006; Sims \& Colunga, 2010). In any case, the interplay of individual and developmental factors in generic language production is a rich source of information regarding conceptual development.

\section{References}

Au, T. K. (1986). A verb is worth a thousand words: The causes and consequences of interpersonal events implicit in language. Journal of Memory and Language, 25, 104-122. doi:10.1016/0749-596X(86)90024-0

Beckage, N., Smith, L., \& Hills, T. (2011). Small worlds and semantic network growth in typical and late talkers. PLoS One, 6, e19348. doi:10.1371/journal.pone. 0019348

Borovsky, A., \& Elman, J. (2006). Language input and categories: A relation between cognition and early word learning. Journal of Child Language, 33, 759-790. doi:10. 1017/S0305000906007574

Brandone, A. C., \& Gelman, S. A. (2009). Differences in preschoolers' and adults' use of generics about novel animals and artifacts: A window onto a conceptual divide. Cognition, 110, 1-22. doi:10.1016/j.cognition. 2008.08.005

Brown, R., \& Fish, D. (1983). The psychological causality implicit in language. Cognition, 14, 237-273. doi:10. 1016/0010-0277(83)90006-9

Carlson, G. N., \& Pelletier, F. J. (Eds.) (1995). The generic book. Chicago, IL: University of Chicago Press.

Cimpian, A., Arce, H. C., Markman, E. M., \& Dweck, C. S. (2007). Subtle linguistic cues affect children's motivation. Psychological Science, 18, 314-316. doi:10.1111/j. 1467-9280.2007.01896.x

Cimpian, A., Brandone, A. C., \& Gelman, S. A. (2010). Generic statements require little evidence for acceptance but have powerful implications. Cognitive Science, 34, 1452-1482. doi:10.1111/j.1551-6709.2010.01126.x

Cimpian, A., \& Markman, E. M. (2008). Preschool children's use of cues to generic meaning. Cognition, 107, 19-53. doi:10.1016/j.cognition.2007.07.008

Cimpian, A., \& Markman, E. M. (2009). Information learned from generic language becomes central to children's biological concepts: Evidence from their open-ended explanations. Cognition, 113, 14-25. doi:10. 1016/j.cognition.2009.07.004

Cimpian, A., \& Salomon, E. (in press). The inherence heuristic: An intuitive means of making sense of the world, and a potential precursor to psychological essentialism. Behavioral and Brain Sciences.

Csibra, G., \& Gergely, G. (2009). Natural pedagogy. Trends in Cognitive Sciences, 13, 148-153. doi:10.1016/j. tics.2009.01.005

Dahl, O. (1975). On generics. In E. Keenan (Ed.), Formal semantics of natural language (pp. 99-111). Cambridge, UK: Cambridge University Press.

Dweck, C. S. (2006). Mindset. New York, NY: Random House.

Gelman, S. A. (2003). The essential child: Origins of essentialism in everyday thought. New York, NY: Oxford University Press.

Gelman, S. A. (2009). Learning from others: Children's construction of concepts. Annual Review of Psychology, 60, 115-140. doi:10.1146/annurev.psych.59.103006. 093659

Gelman, S. A., \& Bloom, P. (2007). Developmental changes in the understanding of generics. Cognition, 105, 166-183. doi:10.1016/j.cognition.2006.09.009

Gelman, S. A., Chesnick, R., \& Waxman, S. R. (2005). Mother-child conversations about pictures and objects: Referring to categories and individuals. Child Development, 76, 1129-1143.

Gelman, S. A., Coley, J. D., Rosengren, K., Hartman, E., \& Pappas, A. (1998). Beyond labeling: The role of maternal input in the acquisition of richly-structured categories. Monographs of the Society for Research in Child Development, 63(1, Serial No. 253). doi:10.2307/1166211

Gelman, S. A., Goetz, P. J., Sarnecka, B. S., \& Flukes, J. (2008). Generic language in parent-child conversations. Language Learning and Development, 4, 1-31. doi:10. 1080/15475440701542625

Gelman, S. A., \& Heyman, G. D. (1999). Carrot-eaters and creature-believers: The effects of lexicalization on children's inferences about social categories. Psychological Science, 10, 489-493. doi:10.1111/1467-9280.00194

Gelman, S. A., Heyman, G. D., \& Legare, C. H. (2007). Developmental changes in the coherence of essentialist beliefs about psychological characteristics. Child Development, 78, 757-774. doi:10.1111/j.1467-8624.2007.01031.x

Gelman, S. A., \& Raman, L. (2007). This cat has nine lives? Children's memory for genericity in language. Developmental Psychology, 43, 1256-1268. doi:10.1037/ 0012-1649.43.5.1256

Gelman, S. A., \& Tardif, T. (1998). A cross-linguistic comparison of generic noun phrases in English and Mandarin. Cognition, 66, 215-248. doi:10.1016/S0010-0277(98) 00021-3

Gelman, S. A., Taylor, M. G., \& Nguyen, S. (2004). Mother-child conversations about gender: Understanding the acquisition of essentialist beliefs. Monographs of the Society for Research in Child Development., 69(1, Serial No. 275), doi:10.1111/j.1540-5834.2004.06901001.x 
Gelman, S. A., Ware, E., \& Kleinberg, F. (2010). Effects of generic language on category content and structure. Cognitive Psychology, 61, 273-301. doi:10.1016/j.cog psych.2010.06.001

Gelman, S. A., Ware, E. A., Manczak, E. M., \& Graham, S. A. (2013). Children's sensitivity to the knowledge expressed in pedagogical and non-pedagogical contexts. Developmental Psychology, 49, 491-504. doi:10.1037/a0027901

Graham, S. A., Nayer, S. L., \& Gelman, S. A. (2011). Twoyear-olds use the generic/nongeneric distinction to guide their inferences about novel kinds. Child Development, 82, 493-507. doi:10.1111/j.1467-8624.2010.01572.x

Gunderson, E. A., Gripshover, S. J., Romero, C., Dweck, C. S., Goldin-Meadow, S., \& Levine, S. C. (2013). Parent praise to 1 - to 3 -year-olds predicts children's motivational frameworks 5 years later. Child Development, 84, 1526-1541.

Hart, B., \& Risley, T. R. (1995). Meaningful differences in the everyday experience of young American children. Baltimore, MD: Brookes.

Heyman, G. D., \& Diesendruck, G. (2002). The Spanish ser/estar distinction in children's reasoning about human psychological characteristics. Developmental Psychology, 38, 407-417. doi:10.1037/0012-1649.38.3.407

Hoff, E. (2006). How social contexts support and shape language development. Developmental Review, 26, 55-88. doi:10.1016/j.dr.2005.11.002

Hollander, M. A., Gelman, S. A., \& Raman, L. (2009). Generic language and judgments about category membership: Can generics highlight properties as central? Language and Cognitive Processes, 24, 481-505. doi:10. 1080/01690960802223485

Hollander, M. A., Gelman, S. A., \& Star, J. (2002). Children's interpretation of generic noun phrases. Developmental Psychology, 38, 883-894. doi:10.1037/0012-1649. 38.6.883

Huttenlocher, J., Waterfall, H., Vasilyeva, M., Vevea, J., \& Hedges, L. V. (2010). Sources of variability in children's language growth. Cognitive Psychology, 61, 343-365. doi:10.1016/j.cogpsych.2010.08.002

Jost, J. T., Glaser, J., Kruglanski, A. W., \& Sulloway, F. J. (2003). Political conservatism as motivated social cognition. Psychological Bulletin, 129, 339-375. doi:10.1037/ 0033-2909.129.3.339

Landis, J. R., \& Koch, G. G. (1977). The measurement of observer agreement for categorical data. Biometrics, 33, 159-174. doi:10.2307/2529310

Lawler, J. (1973). Studies in English generics. PhD dissertation, University of Michigan, Ann Arbor.

Leslie, S.-J. (2007). Generics and the structure of the mind. Philosophical Perspectives, 21, 375-403. doi:10.1111/j. 1520-8583.2007.00138.x

Mannheim, B., Gelman, S. A., Escalante, C., Huayhua, M., \& Puma, R. (2011). A developmental analysis of generic nouns in Southern Peruvian Quechua. Language Learning and Development, 7, 1-23. doi:10.1080/ 15475441003635620
Medin, D. L. (1989). Concepts and conceptual structure. American Psychologist, 44, 1469-1481. doi:10.1037/0003066X.44.12.1469

Naigles, L. R. (2000). Manipulating the input: Studies in mental verb acquisition. In B. Landau, J. Sabini, J. Jonides, \& E. L. Newport (Eds.), Perception, cognition, and language: Essays in honor of Henry and Lila Gleitman (pp. 245-274). Cambridge, MA: MIT Press.

Niederhoffer, K. G., \& Pennebaker, J. W. (2002). Linguistic style matching in social interaction. Journal of Language and Social Psychology, 21, 337-360. doi:10.1177/ 026192702237953

Pappas, A., \& Gelman, S. A. (1998). Generic noun phrases in mother-child conversations. Journal of Child Language, 25, 19-33. doi:10.1017/S0305000997003292

Pelletier, F. J. (Ed.). (2010). Kinds, things, and stuff: The cognitive side of generics and mass terms (New Directions in Cognitive Science, Vol. 12.). New York, NY: Oxford University Press.

Pennebaker, J. W. (2011). The secret life of pronouns: What our words say about us. New York, NY: Bloomsbury.

Pickering, M. J., \& Garrod, S. (2004). Toward a mechanistic psychology of dialogue. Behavioral and Brain Sciences, 27, 169-226. doi:10.1017/S0140525X04000056

Prasada, S. (2000). Acquiring generic knowledge. Trends in Cognitive Sciences, 4, 66-72. doi:10.1016/S1364-6613 (99)01429-1

Rhodes, M., \& Gelman, S. A. (2009). A developmental examination of the conceptual structure of animal, artifact, and human social categories across two cultural contexts. Cognitive Psychology, 59, 244-274. doi:10.1016/j.cogpsych.2009.05.001

Rhodes, M., Leslie, S. J., \& Tworek, C. M. (2012). Cultural transmission of social essentialism. Proceedings of the National Academy of Sciences, 109, 13526-13531. doi:10. 1073/pnas.1208951109

Segall, G., \& Diesendruck, G. (2013, April). The intergenerational transmission of social essentialism. Paper presented at the biennial meeting of the Society for Research in Child Development, Seattle, WA.

Shimpi, P. M., Gámez, P. B., Huttenlocher, J., \& Vasilyeva, M. (2007). Syntactic priming in 3- and 4-year-old children: Evidence for abstract representations of transitive and dative forms. Developmental Psychology, 43, 1334-1346. doi:10.1037/0012-1649.43.6.1334

Sims, C. E., \& Colunga, E. (2010). When comparison helps: The role of language, prior knowledge, and similarity in categorizing novel objects. In S. Ohlsson \& R. Catrambone (Eds.), Proceedings of the 32nd Annual Conference of the Cognitive Science Society (pp. 339-404). Austin, TX: Cognitive Science Society.

Tardif, T., Gelman, S. A., Fu, X., \& Zhu, L. (2012). Acquisition of generic noun phrases in Chinese: Learning about lions without an "-s." Journal of Child Language, 30, 1-32. doi:10.1017/S0305000910000735

Tardif, T., Gelman, S. A., \& Xu, F. (1999). Putting the "noun bias" in context: A comparison of English and 
Mandarin. Child Development, 70, 620-635. doi:10.1111/ 1467-8624.00045

Taylor, M. G., Rhodes, M., \& Gelman, S. A. (2009). Boys will be boys, cows will be cows: Children's essentialist reasoning about human gender and animal development. Child Development, 79, 1270-1287. doi:10.1111/j. 1467-8624.2009.01272.x

Trautner, H. M., Ruble, D. N., Cyphers, L., Kirsten, B., Behrendt, R., \& Hartmann, P. (2005). Rigidity and flexibility of gender stereotypes in childhood: Developmental or differential? Infant and Child Development, 14, 365-380. doi:10.1002/icd.399

Walton, G. M., \& Banaji, M. R. (2004). Being what you say: The effect of essentialist linguistic labels on preferences. Social Cognition, 22, 193-213. doi:10.1521/soco.22.2.193.35463

Ware, E. A., Gelman, S. A., \& Kleinberg, F. (2013). The medium is the message: Pictures and objects evoke distinct conceptual relations in parent-child conversations. MerrillPalmer Quarterly, 59, 50-78. doi:10.1353/mpq.2013.0004

Waxman, S. R., \& Leddon, E. M. (2011). Early word learning and conceptual Development: Everything had a name, and each name gave birth to a new thought. In U. Goswami (Ed.), The Wiley-Blackwell handbook of childhood cognitive development (pp. 180-208). Malden, MA: Wiley-Blackwell.

$\mathrm{Xu}, \mathrm{F}$. (2007). Sortal concepts, object individuation, and language. Trends in Cognitive Sciences, 11, 400-406. doi:10.1016/j.tics.2007.08.002

\section{Appendix \\ Wording of Questionnaire in Study 1, Using "Shy" as Sample Characteristic}

Birth versus adoptive parents-Will a baby who is adopted at birth grow up to be as shy as the birth parents, or as shy as the adoptive parents? $(1=$ adoptive parents, 6 = birth parents $)$.

Born-Are some people born with a predisposition to be shy? $(1$ = definitely no, $6=$ definitely yes $)$

Change-To what extent can people change whether they are shy, if they want to? $(1=$ not at all, $6=$ a lot)

Consistent-Do people who are shy at age 20 tend to be shy at age 40? $(1=$ definitely no, $6=$ definitely yes)

Environment-How much does the environment a person grows up in, affect whether or not he or she will become shy? $(1=$ not at all, $6=a$ lot $)$

Genes-In the future, will scientists be able to determine which people are shy by testing their genes? $(1=$ definitely no, $6=$ definitely yes $)$

Infancy-Do you think scientists will ever be able to tell which babies will grow up to be shy? $(1$ = definitely no, 6 = definitely yes $)$ 